\title{
IMMEDIATE DENTURE: A REVIEW
}

\section{Dental Science}

Dr. Dipti Nayak

Dr. Romil Singhal*

Dr. Samarth

Agarwal

Dr. Sabeeha

Hussain

\section{Dr. Beenish Javed}

\section{Dr. Shalini Gupta}

Post Graduate student, Department of Prosthodontics and Crown \& Bridge, Kothiwal Dental College \& Research Centre, Moradabad-244001, Uttar Pradesh, India.

Professor, Department of Prosthodontics and Crown \& Bridge, Kothiwal Dental College \& Research Centre, Moradabad-244001, Uttar Pradesh, India. *Corresponding Author

Professor, Department of Prosthodontics and Crown \& Bridge, Kothiwal Dental College $\&$ Research Centre, Moradabad-244001, Uttar Pradesh, India

Post Graduate student, Department of Prosthodontics and Crown \& Bridge, Kothiwal Dental College \& Research Centre, Moradabad-244001, Uttar Pradesh, India.

Post Graduate student, Department of Prosthodontics and Crown \& Bridge, Kothiwal Dental College \& Research Centre, Moradabad-244001, Uttar Pradesh, India.

Professor, Department of Periodontics, Uttaranchal Dental College \& Medical Research Institute, Dehradun-Uttarakhand 248140, Uttar Pradesh, India.

\section{ABSTRACT}

An immediate denture is a prosthesis placed immediately following tooth extraction due to esthetic reason. It is used to enhance esthetics, protect extraction related surgical wound and provide function during healing. This type of transitional denture is often associated with a larger number of teeth being extracted on the day of prosthesis insertion and a higher degree of unpredictability relative to anticipated healing. Consequently, the required treatment addresses an immediate denture that will ultimately be transitioned into a definitive prosthesis.

\section{KEYWORDS}

conventional immediate denture, interim, transitional

\section{INTRODUCTION}

An immediate complete denture is a restoration fabricated prior to the extraction of a tooth, which is placed in the patient's mouth immediately following the removal of the remaining teeth. They are fabricated increasingly nowadays, mainly for aesthetic and psychological reasons.

The success of immediate dentures depends on correct indication and precise execution of clinical and laboratory fabrication procedures. Usually posterior teeth are removed, leaving the six anterior teeth in position and allowed for an adequate healing period of 8 to 12 weeks before the final impressions are made for the definitive prostheses.

An immediate denture is classified as:

A. Conventional immediate denture- one placed after healing is completed and denture is relined to serve as the long-term prosthesis.

$B$. Interim or Transitional immediate denture- prosthesis is designed to enhance esthetics, stabilization and or function for a limited period of time, after which it is replaced by a definitive prosthesis.

C. Lavere and krol classified immediate dentures as conventional immediate dentures, transitional dentures or diagnostic dentures (splint) and each further into groups as having a labial flange, partial labial flange, flangeless immediate denture.

\section{DIAGNOSIS TREATMENT PLANNING AND PROGNOSIS} Patient assessment

The periodontal status, caries rate and current state of edentulism must be considered. Debridement of the existing teeth should be done with an initial prophylaxis followed by oral hygiene instructions. The health of the remaining dentition must be assessed and the strategic nature of salvageable teeth also should be considered. Irregularities in occlusal plane and opposing dentition must be evaluated as the retention of strategically malposition teeth could result in adverse force transmission to the underlying structures, thereby resulting in greater functional and anatomical deficit.

Indications for immediate denture ${ }^{4}$

Physical reasons:

1. Disuse atrophy of the bony base,

2. Unfavorable trabeculation of the repairing bone,

3. Damage of the temporomandibular joints,

\section{Physiologic reasons:}

1.Abnormal functioning of the mouth and mandible

2. Impaired enunciation,

3. Abnormal deglutition

Psychologic reasons:

1. Humiliation,

2. adverse subjective reactions,

3. serving the indifferent patient

\section{Contraindications for immediate denture $\mathrm{e}^{5}$}

1. Diseases of a debilitating nature e.g., post irradiation of the head and neck regions, systemic conditions that affect healing or blood clotting, cardiac or endocrine gland disturbances, and psychological disorders) $)^{2}$. Extreme deep overbites or other abnormalities that make balanced occlusion impossible.

2. Multiple extractions might be unwise because of systemic conditions.

3. Emotionally disturbed individuals

4. Mental incapacities

5. Indifferent unappreciative patients

6. Acute periapical or periodontal pathosis

7. Extensive bone loss adjacent to remaining teeth.

\section{Oral examination and informed consent}

The panoramic radiograph provides a useful diagnostic aid. After reviewing the dental and medical history of the patient, head and neck examination is performed. During the normal intraoral examination, the dentist should include and record periodontal probing, a full charting of all the teeth, need for frenum release, tori reduction or any other hard and soft tissue surgery if necessary .When possible, teeth should be selected for retention as overdenture abutments.

The normal and the common anatomic abnormal difficulties of the mouth relative to immediate denture insertion is classified as: (1) Hard tissues (exostoses, spiculae, mylohyoid ridges, knife-edge ridges, maxillary tuberosity and alveolar contour) (2) Soft tissues (abnormal frenula and ligament and muscle attachments) (3) Ridge relation (faulty ridge relationship). ${ }^{7}$ Also notation of following factors help in later visits like 1. Existing midline and need for modification of its position 2. Patient's existing vertical dimension of occlusion and amount of interocclusal distance and the need for conforming to or 
changing it 3 . Horizontal and vertical overlap of anterior teeth 4 . Type of angle's classification of occlusion for the patient, 5. Display of posterior tooth in the buccal corridor

\section{Tooth modification}

Many immediate dentures will require modification of opposing teeth to correct the occlusal plane or to eliminate prematurities in centric relation. They can also interfere with the proper determination of the occlusal vertical dimension. It is determined best by performing a diagnostic mounting of the preliminary casts to carefully evaluate the planned changes.

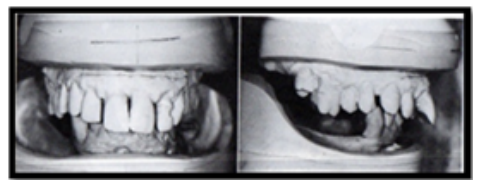

Figure 1: Mounted diagnostic casts ${ }^{2}$

\section{First extraction or surgical visit}

For preliminary extractions in conventional immediate denture technique, the patient's posterior teeth are removed as soon as possible. Any other required hard and soft tissue operation is also done at first surgical visit. These posterior extraction and other operated areas are allowed to heal for a short time usually 3 to 4 weeks.

\section{Preliminary impressions and diagnostic casts}

Preliminary impressions are made for two primary reasons. The first is to use these impressions in the fabrication of casts that will be used in diagnosis and treatment planning. The second purpose is for fabrication of custom impression trays. Regardless of the technique, the clinician will identify a peripheral extension to which the custom tray should extend. Then a custom tray is fabricated with an appropriate amount of space between the natural teeth and the impression tray. This relief is easily controlled by the application of a specified thickness of wax (generally 1 to $3 \mathrm{~mm}$ ) that is adapted to the soft and hard tissues of the diagnostic cast.

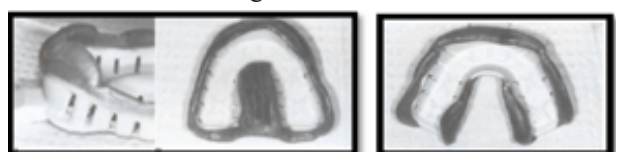

Fig 2: Maxillary tray border molded

\section{Mandibular tray border molded}

Loose teeth can be protected from extractions during preliminary or final impression by blocking out by adding periphery wax at the cervical area.

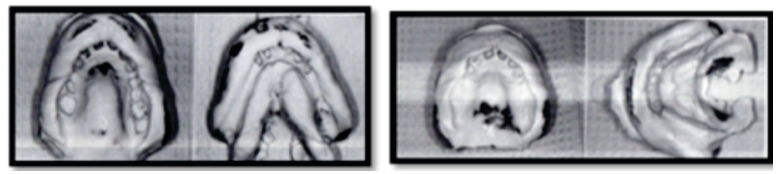

Fig 3: Maxillary and mandibular preliminary impressions for IID and CID ${ }^{2}$

\section{Custom trays and final impressions}

Two fundamental techniques have been described to make final impressions for an immediate denture. The two techniques consist of using either a single impression tray that captures the natural dentition and the soft tissues simultaneously or creating an impression that uses a tray to capture the posterior soft tissue while a second tray is adapted to the first in an effort to capture the anterior teeth in the secondary impression.

A single impression tray may be used when anterior and or posterior teeth remain. This technique is most useful when the teeth maintain positional stability and would not be displaced by the impression. On the contrary, if the soft tissue is compressible, the single tray approach may provide an opportunity to impress this tissue while at rest, using the remaining natural teeth to act as a tray stop when inserting the impression tray. This technique may require border molding in the edentulous areas to establish the full peripheral extension. The flange in the dentate areas should be extended with border molding material toward the tissue reflection, but tissue undercuts may prevent the border molding material from establishing full contact with vestibular tissue. Once border molding is established, the final impression is made using an elastomeric impression material.

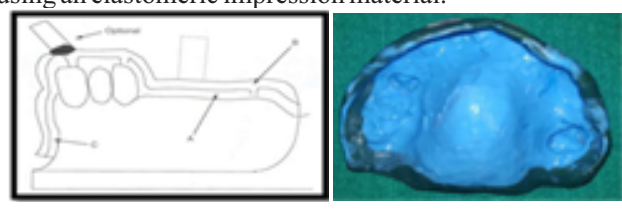

Fig 4: Wax Block-Out for CID ${ }^{2}$ and final impression

Type two: Two- tray or sectional custom impression tray

The type two method is used only when the posterior teeth have been removed as for conventional immediate denture. It cannot be used in the interim immediate denture technique because usually there are posterior teeth present. It involves fabricating two trays on the same cast, one in the posterior, which is made like a complete denture tray, and one in the anterior (backless tray). An alternative impression technique would be to use an impression tray in the posterior portion of the oral cavity to impress the soft tissue only. This tray would then be indexed in such a way that it would connect to an anterior tray that would capture the likeness of the anterior teeth at rest. This approach is particularly effective when the anterior teeth are quite mobile and if the position of these teeth would be difficult to capture in a single impression technique. After border molding the posterior impression tray, an elastomeric material is used to capture the tissues at rest. If no undercuts exist in the soft or the hard tissue, these tissues could be recorded with zinc oxide eugenol impression material. The anterior segment is recorded with an elastomeric impression material. Regardless of the impression technique, the posterior limit of the maxillary complete denture must be established to create a posterior palatal seal.

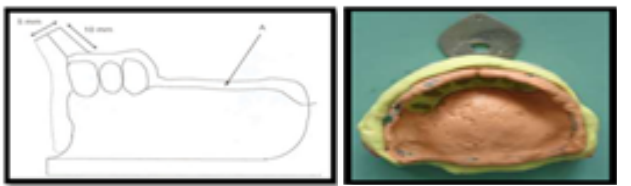

Fig 5: Sectional Custom Impression Tray ${ }^{2}$ and final impression

The most important consideration in the sectional tray technique is the careful, proper reassembly of the two separate components of the impression. Care must be taken not to distort this assembly during removal from the mouth and during the pouring of the impression. The method of boxing the impression with a mixture of plaster and pumice is suggested as least likely to cause distortion. The final casts are trimmed.

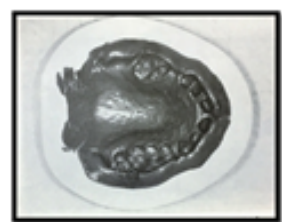

Fig 6: Plaster and Pumice (50:50) Mix for Boxing

Another tray variation for the maxilla is campagna tray technique. It looks like a full arch tray with a hole cut out for the remaining anterior teeth. A stock tray is used over the full arch tray to capture the anterior teeth in the impression. ${ }^{8}$

According to Swenson, kerr's utility wax added along the borders to extend from tuberosity to tuberosity and centre of the palatal area. Wax is softened just before placement and alginate is added. Posterior part of tray is prepared with modelling compound. Tooth contact with compound is avoided. A small amount of heated hydrocolloid is expelled with a syringe over anterior portion of exposed tray. Additional amount of hydrocolloid is added over remainder of the tray. Tray is placed in mouth and cooled through water jacket.

Lambrecht technique'- Anteriorly, the flanges extending labially beyond the teeth to extend one eighth of an inch beyond the labial surfaces of the teeth. After all the adjustments have been made, the tray is trimmed and border molded with green stick modeling compound. After the flanges of the tray is perfected and posterior palatal seal established, a static impression is made using zinc oxide eugenol paste or silicone rubber impression material. A labial segment is constructed with the main part of the impression in the mouth using materials as plaster of paris, modeling compound, wax and acrylic resin. With the 
lip reflected, the impression material is painted on the teeth and tissue with a camel's hair brush, carried into position with a spatula, or it is carried under the lip with the fingers. The two sections are reassembled and prepared for cast pouring.

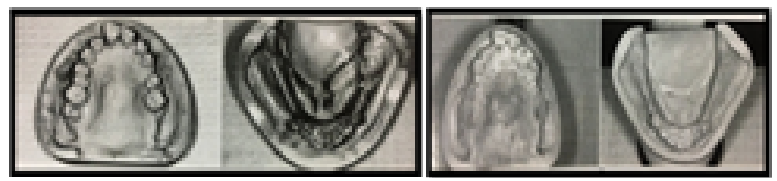

Fig 7: A, Final Casts for IID, B, Final Casts for CID

\section{Maxillomandibular relationship records}

Careful assessment of the dentition in the opposing arch must be made and any alterations in its form, so as to establish a more favorable occlusion.

The centric relation record is made directly at the established vertical dimension using the clinician's material of choice like bite registration wax, plaster or zinc oxide and eugenol.
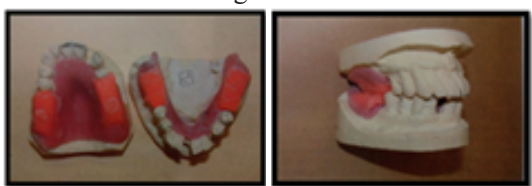

\section{Fig 8: Centric relation record}

\section{Denture teeth arrangement}

The posterior teeth may then be used in a clinical trial of the wax trial denture to ensure that the appropriate vertical dimension and centric occlusion positions have been established. Once again phonetics and facial support will all be considered when confirming the vertical and horizontal positions.

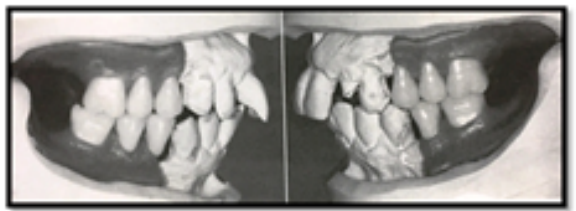

Fig 9: Posterior Tooth Setup for Try-in for CID

\section{Laboratory procedures}

The immediate denture differs from the traditional denture in that the cast must be modified to represent the anticipated changes in contour that will occur with surgical removal of teeth. The preliminary step in cast modification is the dental midline established by removing the central incisor and coinciding with the facial midline. The midline is marked in pencil on the cast.

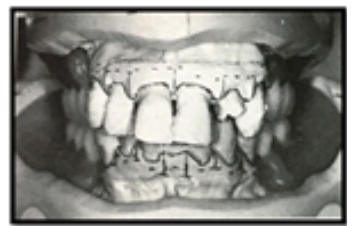

Fig 10: Casts and land area marked with new midline ${ }^{2}$

The posterior teeth already have been arranged; consequently, the remaining teeth may be removed from the stone cast and the cast adjusted to simulate the soft and hard tissue contours that would be anticipated following removal of teeth. The clinician needs to remain aware that natural teeth are supported in an alveolus that may be as little as $2 \mathrm{~mm}$ below the free gingival margin or could be as much as a centimeter or more below this soft tissue margin. Tissue depth is critical as this influence the thickness of the tissue beneath the immediate denture.
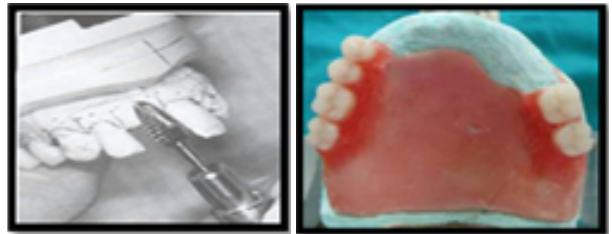

Fig 11: Extraction sites marked ${ }^{2}$ and trimmed
According to swenson ${ }^{10}$ - root portion is excavated to a depth of approx $2 \mathrm{~mm}$ on the labial side and flush with the gingival area on the lingual side, According to heartwell - labial line should be $3 \mathrm{~mm}$ above gingival and palatal line $2 \mathrm{~mm}$ above gingiva, According to rudd \& morrow ${ }^{11}$ labial surfaces of lower anterior teeth labially $2 \mathrm{~mm}$ depth and palatally at gingival line.

As suggested by Kelly, it is a modification of the "rule of thirds", which recommends dividing the labial aspect of the ridge into three equal bands of space between the gingival line and the depth of the vestibular space. Trimming of the labial portion of the cast begins at the labio-tolingual center of the ridge and is confined to the gingival and middle thirds, with most of the trimming done in the gingival third. The lingual portion of the cast is contoured and smoothed by again starting at the labio-to-lingual center of the ridge.

Decoronation- woloch (1998) - Instead of extracting the remaining anterior teeth, decoronation (with pulpectomy as indicated) of the crowns should be done. The roots are removed after several days through 2 to 3 weeks.

According to fenn - Main types of socket preparation are with anterior teeth socketed (socket are deepened by 1-2 mm leaving margins intact), labial flange without alveolectomy (sockets not carved while labial part of gingival margin is scraped), labial flange with alveolectomy (sockets are carved deeper and labial plate is reduced in area of attached mucosa).

If the labial plate of bone is relatively intact within a few millimeters of the free gingival margin before removal of the tooth from the cast, then remove the tooth from the cast at the gingival crest and then hollow grind the cast a similar number of millimeters to simulate tooth removal. Simply put, more pocketing demands deeper preparation of the cast. Once the depth of the alveolus is approximated, the labial soft tissue can then be reduced to simulate the drape of the tissue over the labial plate of bone.

Once "cast surgery" has been performed and the irregularities on the cast have been corrected through smoothing and polishing, the remaining denture teeth may be arranged.

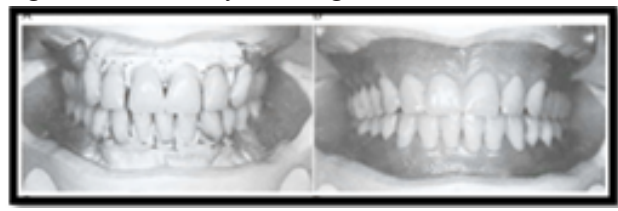

Fig 12: Teeth setup and wax up

The complete wax trial denture may then be removed from the cast so that a duplicate impression can be made. This duplicate impression would then be poured with stone and two layers of baseplate wax adapted to it; this will be invested, packed with clear acrylic resin, processed, finished, polished and used as the surgical template.

The denture is fabricated using similar traditional technology using a split pack or injection molding technique. Following processing, the denture are deflasked and remounted. Occlusal adjustment is performed to eliminate processing error, to reestablish the predetermined occlusal vertical dimension and to provide bilateral balanced occlusion. The denture is then finished and polished.

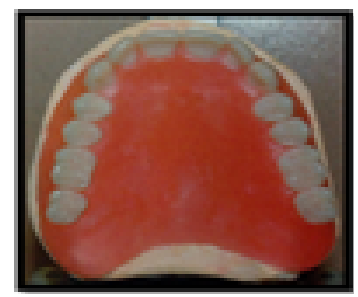

Fig 13: Final denture

\section{Teeth removal and denture insertion}

Tooth removal is performed carefully to maintain the integrity of the labial and palatal or lingual bony plates. If the decision was made to alter the contour of the bone, this will be accomplished at this time. The 
surgical template will be inserted before closure of the surgical site and any areas of tissue blanching, which will be evident through the clear template, should be corrected by minor alveoloplasty.

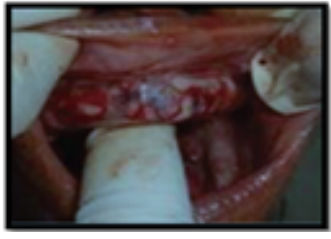

Fig 14: Surgical template

Once the clinician has eliminated areas of tissue blanching, the immediate denture will then be inserted on a trial basis. Pressure indicator paste may be valuable to identify areas of tissue impingement. The patient will be instructed not to remove their immediate denture for 24 hours.

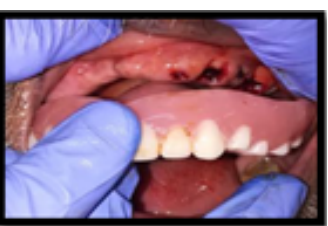

Fig 15: Anterior alveolectomy and denture insertion

The patient will return to the dental office during that 24-hour time frame when the denture will be removed by the clinician and adjusted accordingly to eliminate soft tissue irritation and diminished denture retention

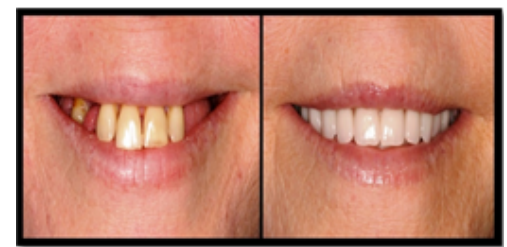

Fig 16: Conventional immediate denture

\section{Postoperative care}

The patient will be seen in 24 hours to evaluate denture retention, support, and stability.

\section{First 24 Hours $^{2}$}

The patient should avoid rinsing, avoid drinking hot liquids or alcohol and not remove the immediate dentures during the first 24 hours. Because inflammation, swelling and discoloration are likely to occur, their partial control can be helped with ice packs (20 minutes on, 20 minutes off) on the first day. Analgesic medications are prescribed as required. The diet for the first 24 hours should be liquid or soft, if tolerated.

\section{At the 24 hour visit:}

1. Quickly check the tissues for sore spots (strawberry-red) related to the dentures. Usually, areas include canine eminences, lateral to tuberosities; posterior limit areas and retromylohyoid undercuts as well as any other undercut ridge areas. They are relieved in the acrylic resin. The denture should be kept out of the mouth only for a very short time. Place a tissue conditioner if denture retention is unsatisfactory.

\section{First Postoperative Week}

Counsel the patient to continue to wear the immediate denture at night for 7 days after extraction or until swelling reduction. After 1 week, sutures can be removed and patient can begin removing the denture at night. A reline or rebase of the denture is anticipated within the first year of clinical service.

\section{Digital Immediate Denture}

Digital dentures are fabricated using CAD/CAM technology. They reduce clinical appointments, provide high accuracy in denture fit, allow less polymerization shrinkage of the denture base and facilitate easier duplication of dentures.

\section{CONCLUSIONS}

Immediate dentures fulfill an important role in today's treatment modalities by providing the patients with esthetics, function, and psychological support after extractions and during the healing phase. Proper follow-up care is essential to the success of an immediate denture.

\section{REFERENCES:}

[1] Zarb GA, Bolender CL, Eckert SE, Jacob RF, Fenton AH. Prosthodontic treatment for edentulous patients: complete dentures and implant supported prosthesis. 13th ed. Elsevier:2013;pg.281-90

[2] Zarb GA, Bolender CL, Eckert SE, Jacob RF, Fenton AH. Prosthodontic treatment fo edentulous patients: complete dentures and implant-supported prosthesis. 12th ed.Elsevier:2004; pg.123-59.

[3] Lavere am and krol aj. Immediate denture service. J Prosthet Dent. 1973;29(1): 10-5.

[4] Devan $\mathrm{mm}$. The transition from natural to artificial teeth. J Prosthet Dent 1961;11(4):677-88.

[5] Heartwell, cm, jr., and salisbury fw. Immediate complete dentures: an evaluation. J Prosthet Dent 1965;15(4):615-24

[6] Heartwell CM, Rahn AO. Syllabus of complete denture. 4th ed. varghese publishing house: $1992 ;$ pg.457-82

[7] Maison WG. Preparation of the mouth and casts for immediate dentures. J Prosthet Dent Jan 1953;3(1): 66-81.

[8] Campagna SJ. An impression technique for immediate dentures. J Prosthet Dent. 1968; 20(3):196-203.

[9] Lambrecht JR. Immediate denture construction; The impression phase. J Prosthet Dent 1968;19(3),237-45.

[10] Swenson MG, Stout CJ. Complete denture. 6th ed. Mosby company:1964;pg.405-68.

[11] Morrow $\mathrm{r} \mathrm{m}$, rudd $\mathrm{k} \mathrm{d}$ and rhoads $\mathrm{j}$ e. Dental laboratory procedures complete dentures. 2nd ed. Mosby co: 1986; pg.413-24

[12] Jerbi fc. Trimming of the cast in the construction of immediate complete dentures. J Prosthet Dent 1966;16(6): 1048-51.

[13] Fenn hrb, linddelow kp, gimpson ap. Clinical dental prosthesis. 5th ed. Cbs publishers: 2008;pg. 290-96. 